\title{
Bilateral schizencephaly Type II
}

\author{
Neetu Sharma ${ }^{1}$, Rajdhar Dutt ${ }^{1}$, Vikas Agarwal $^{2}$, Pankaj Yadav ${ }^{3}$
}

1. Department of Pediatrics, GR Medical College, Gwalior, MP, India

2. Consultant Pediatrician, Gwalior, MP, India

3. Department of Radiodiagnosis, GR Medical College, Gwalior, MP, India

\section{CASE REPORT}

Please cite this paper as: Sharma N, Dutt R, Agarwal V, Yadav P. Bilateral schizencephaly Type II. AMJ 2014, 7, 3, 157-160. http://doi.org/10.21767/AMJ.2014.1924

\section{Corresponding Author:}

Dr Neetu Sharma

C-36, Jawahar Colony, Gwalior, Madhya Pradesh, India

Email: drneetuagarwal@gmail.com

\section{ABSTRACT}

\section{Background}

Schizencephaly is one of the most severe forms of neuronal migration defects and is an extremely rare cause of seizure disorder.

\section{Case details}

We report a case of bilateral schizencephaly (Type II) presenting as seizure disorder since birth.

\section{Discussion}

This case is rare because of the relatively benign features compared to other reported cases.

\section{Conclusion}

Compared to other cases, this patient has normal cognitive and motor functioning. Given the scant literature on schizencephaly in India's paediatric population, this case highlights the possibility of a very rare entity associated with seizures. MRI can detect this condition.

\section{Key Words}

Bilateral schizencephaly type II, seizure disorder

\section{Implications for Practice:}

\section{What is known about this subject?}

Schizencephaly is one of the most severe forms of neuronal migration defects and is extremely rare.

\section{What is the key finding in this case study?}

Bilateral clefts are generally known to be associated with severe cognitive and/or motor problems, but in this case development was normal.

\section{What are the implications for future practice?}

This reported case shows that the severity of cognitive and motor deficit may not be directly proportionate to the extent of anatomical defect.

\section{Background}

Schizencephaly is the presence of unilateral or bilateral clefts within the cerebral hemispheres due to abnormalities of morphogenesis. This cleft communicates between the subarachnoid space laterally, and ventricular system medially. Yakovlev and Wadswoth first described the condition with two variants by the presence of "fused" cleft in the cerebral mantle (Type I) as opposed to separated cleft with concordant "hydrocephalus" (Type II). ${ }^{1}$ It is an extremely rare disorder; recent estimates show the overall prevalence of 1.54 per 100,000 populations ${ }^{2}$ with very few cases reported from India. 3,4

\section{Case details}

A five-month-old male infant presented with a history of fever over the previous five days. The child was accepting feeds as before. Parents reported that the child was active except during the phases of excessive crying. Periods of excessive crying were noticed since birth. The child, born at term, was the first to a 24-year-old mother (non-consanguineous marriage). The antenatal, intranatal, and perinatal periods were uneventful. Anthropometric measurements for weight and length were within normal limits except the head circumference was $36.5 \mathrm{~cm} \quad\left(<3^{\text {rd }}\right.$ percentile). Upon admission, generalised tonic seizures were noted, which the parents 
had also noticed earlier but considered them to be a part of excessive crying.

On examination there was no dysmorphism of the face, no neurocuteneous markers, cranial nerves were intact, and the child had no physical features of congenital infection. Developmental milestones were age appropriate. Vision and hearing were normal. The patient was admitted with a provisional diagnosis of meningitis, and started on ceftriaxone and phenobarbitone after sending the cerebrospinal fluid for examination. The child became afebrile on day 2 after admission, and irritability decreased on day 4.

Investigations revealed normal haematological profile, electrolytes, and normal cerebrospinal fluid examination. Cranial ultrasound showed mild dilated lateral ventricles. An MRI was performed that revealed open lip schizencephaly (grey matter-lined cleft) extending from the lateral ventricle to the subarachnoid space on either side in the bilateral frontal lobes along with pachygyria involving the bilateral frontoparietal lobes and the absence of septum pellucidum (Figures 1 and 2).

\section{Figure 1: Open lip schizencephaly}

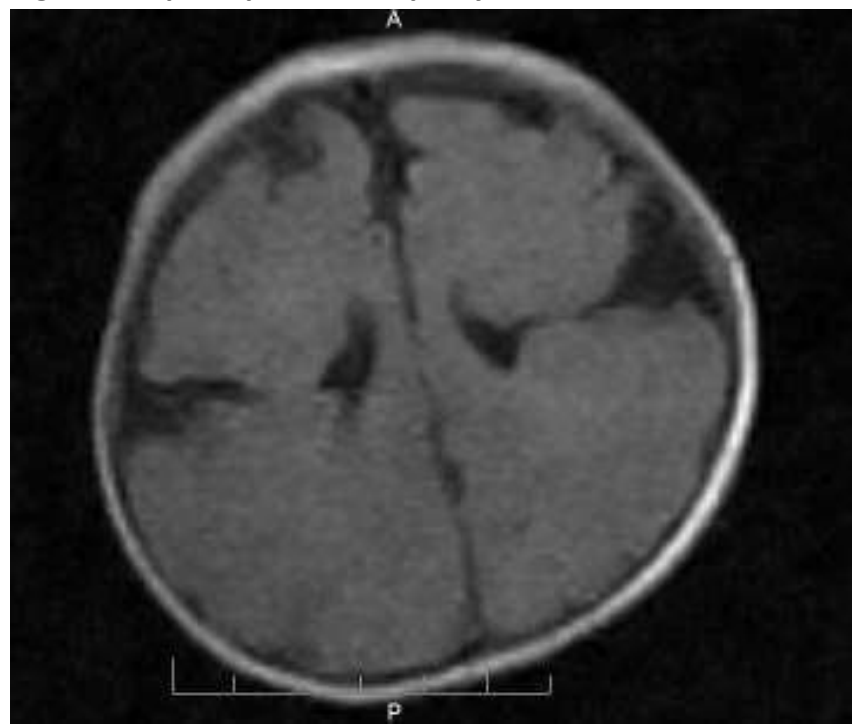

Axial T1-weighted image shows open lip schizencephaly (grey matter-lined cleft) extending from the lateral ventricle to the subarachnoid space on either side in the bilateral frontal lobes.
Figure 2: Absent septum pellucidum

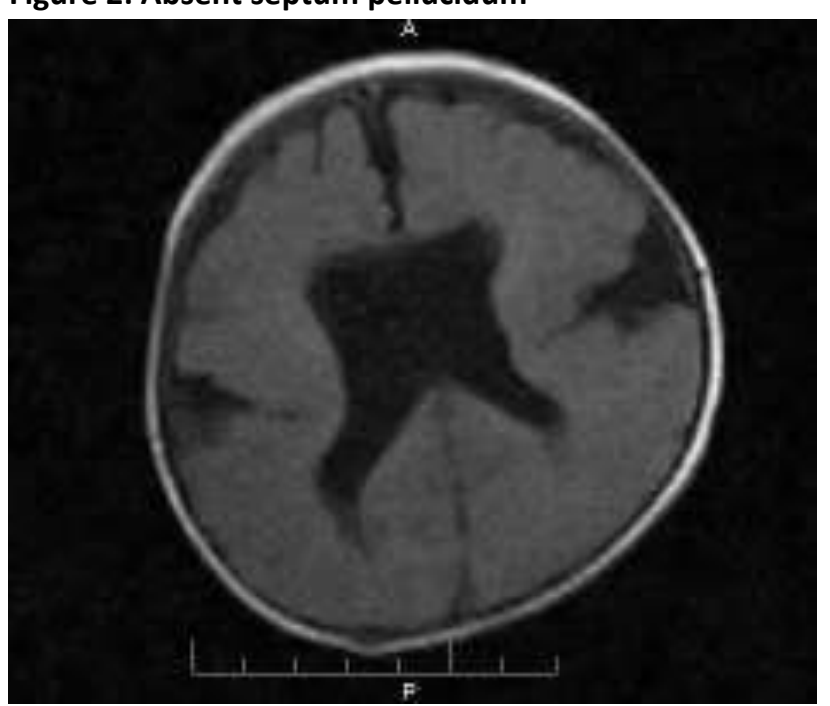

Axial T1-weighted image shows pachygyria involving the bilateral frontoparietal lobes and the absence of septum pellucidum.

The child remained stable without seizures and was discharged on day 14 , on oral phenobarbitone $(5 \mathrm{mg} / \mathrm{kg} /$ day dose). The patient is regularly being followed up, and there has been no episode of seizure one month after discharge.

\section{Discussion}

Schizencephaly is an extremely rare entity responsible for seizure disorder and developmental delay. The exact incidence of Type I schizencephaly is not known. In the literature only approximately 70 cases of Type II schizencephaly have been reported. ${ }^{3}$ In one series of 16 cases, five had bilateral schizencephaly with open lips, two showed unilateral schizencephaly with separate lips, eight presented with unilateral schizencephaly with fused lips, and one had open lips on one side and fused lips on the other. ${ }^{5}$

The exact aetiopathogenesis of schizencephaly is unknown. Failure of normal migration of the primitive normoblasts, due to foetal brain injury is considered a cause. Different theories have been proposed for the supposed fetal brain damage like a vascular injury leading to an infarction in the area of germinal matrix, cytomegalovirus infection, EMX2 gene mutation, herpes virus, maternal trauma, teratogens, alcohol and drug abuse, warfarin, and monozygotic twin interactions. ${ }^{6}$ Therefore, it is considered to be secondary to multiple factors, leading to a final common manifestation of abnormal neuronal migration. However, in our case no known aetiological factor could be identified. 
A clinical profile may range from varying degrees of developmental delays, severe mental retardation, difficult control seizures, delayed language skills, vision, and eating disorders to normal intelligence (very few cases). Patients may also have microcephaly, hydrocephalus, congenital haemiparesis, spastic quadriparesis (partial or complete paralysis), and hypotonicity.

Clinical presentation depends on the size and location of the lesion. Bilateral clefts are generally associated with severe motor deficit, such as spastic quadriparesis, and severe cognitive impairment. One study reported that children with unilateral schizencephaly had a mild or moderate outcome more frequently than those with bilateral lesions (62 per cent versus 28 per cent; $P<0.05){ }^{7}$ Our case, however, despite having bilateral lesions, has normal development. The infant's motor system was essentially normal. The infant only had seizures as compared to other reported cases that show more serious manifestations. ${ }^{3,7}$ There is only one other report of a benign presentation in the presence of a significant MRI finding. ${ }^{8}$

Prenatal ultra sonogram (USG) allows diagnosis of schizencephaly. The lesion may be suspected by the presence of focal ventricular dilatation on USG, but in the Type I variety it may not be able to detect the cleft. ${ }^{3}$ In our case also, the USG (postnatal) showed only mild dilated lateral ventricles.

A CT scan is diagnostic as it can demonstrate the size and extent of the cleft and associated malformations like polymicrogyria, absent septum pellucidum, optic nerve hypoplasia, and agenesis of corpus callosum, but MRI remains the most sensitive and imaging modality of choice as It identifies the milder form, the anomalous grey matter along the cleft as well as the associated abnormalities such as heterotopias. ${ }^{9}$ In our patient, MRI findings showed grey matter-lined cleft extending from the lateral ventricle to the subarachnoid space on either side in the bilateral frontal lobes and pachygyria with an absence of septum pellucidum. This was in contrast to the other reports that had polygyria with many associated brain abnormalities. ${ }^{10,11,12}$

Prognosis varies depending on the size of the clefts and the degree of neurological deficit. Treatment usually consists of physical therapy, occupational therapy, and anticonvulsant, plus in the case of hydrocephalus, a shunt is required. Our case responded well to a single anticonvulsant therapy.

\section{Conclusion}

There is scant literature on schizencephaly in India's paediatric population. Our case highlights the possibility of a very rare entity associated with seizures. MRI can detect this condition in undiagnosed cases of childhood seizures.

\section{References}

1. Yakovlev PI, Wadsworth RC. Schiz-encephalies: A study of the congenital clefts in the cerebral mantle. Clefts with fused lips. J Neuropathol Exp Neuro 1946;5:116-30.

2. Curry CJ, Lammer EJ, Nelson V, Shaw GM. Schizencephaly: Heterogeneous etiologies in a population of 4 million California births. Am J Med Genet A 2005;137:187-9.

3. Dubey AK, Gupta RK, Sharma P, Sharma RK. Schizencephaly type I. Indian Pediatr 2001;8:949-51.

4. Chaitanya Varma $P$ V, Bhat $Y R$, Bhatt $S$. Unilateral open-lip schizencephaly: $A$ rare cause of infantile hemiparesis. J Pediatr Neurosci 2012;7:234-5

5. Pascual-Castroviejo I, Pascual-Pascual SI, VelazquezFragua R, Viaño J, Quiñones D. Schizencephaly: a study of 16 patients [Article in English, Spanish]. Neurología. 2012;27:491-9.

6. Brunelli S, Faiella A, Capra V, Nigro V, Simeone A, Cama A. Germline mutations in the homebox gene EMX2 in patients with severe schizencephaly. Nat Genet. 1996; 12: 94-96.

7. Packard AM, Miller VS, Delgado MR. Schizencephaly Correlations of clinical and radiologic features. Neurology. 1997; 48:1427-1434. doi: 10.1212/WNL.48.5.1427

8. Bansal N, Maini B, Bhardwaj AK, Sharma R. Schizencephaly of open and closed lip type in the same patient: An extremely rare occurrence. J Pediatr Neurosci 2012;7:109-10.

9. Prasad M, lype M, Nair PM. Callosal agenesis and open lip schizencephaly. Indian J Pediatr 2006; 73:838-9. .

10. Avcu S, Ozen O, Unal O. Bilateral giant open lip schizencephaly with associated cerebral anomalies: a case report Cases J. 2009 Apr 27;2:7012. doi: 10.1186/1757-1626-0002-0000007012.

11. Yanase $M$, Kaido $T$, Yamada $M$, Watanabe $M$. Malformations of cortical development with good clinical outcome: a case report and review of literature BMJ Case Reports. 2012;Jun28:2012 doi:10.1136/bcr-11-2011-5219.

12. Choh NA, Choh SA. MRI demonstration of subtotal agenesis of the cerebellum with closed-lip schizencephaly. Ann Saudi Med 2011;31:207-8.

\section{PEER REVIEW}

Not commissioned. Externally peer reviewed 


\section{PATIENT CONSENT}

The authors, Sharma N, Dutt R, Agarwal V, Yadav P, declare that:

1. They have obtained written, informed consent for the publication of the details relating to the patient(s) in this report.

2. All possible steps have been taken to safeguard the identity of the patient(s).

3. This submission is compliant with the requirements of local research ethics committees. 